\title{
IDEIAS E POSSIBILIDADES METODOLÓGICAS DE CONSTRUÇÃO DO CONHECIMENTO HISTÓRICO
}

Carlos Jorge Paixão

Universidade Federal do Pará - UFPA

cjp@ufpa.br

\section{RESUMO}

Este artigo tem por objetivo demonstrar as variações em torno das ideias de história e as possibilidades de construção do conhecimento histórico por meio da pesquisa historiográfica analítica. Na primeira parte do texto, apresentamos sumariamente, diversas definições de história, tomando como referência uma variedade de trabalhos de diversos autores; nas partes seguintes, comentamos sobre o método historiográfico analítico parcial e o método global, e apontamos as possibilidades da construção de historiografias analíticas e parciais, como uma das formas de caminhar no campo denso e complexo da história como ciência.

Palavras-chave: Ideia de História; Método Historiográfico Analítico Parcial; Método Historiográfico Globalizante; Construção do Conhecimento Histórico.

\section{IDEAS AND POSSIBILITIES OF METHODOLOGICAL HISTORIC BUILDING KNOWLEDGE}

\begin{abstract}
This article aims to demonstrate the variations around the ideas of history and the possibilities of construction of historical knowledge through research historiographical analysis. In the first part of the text, we present briefly, various definitions of history, with reference to a variety of works by various authors, in the following sections, we comment on the method historiographical and analytical partial global method, and point out the possibilities of building analytical and historiographies partial, as a way of walking in dense and complex field of history as a science.

Keywords: History of Ideas; Analytical Method historiographical Partial; historiographic method globalizing; Construction of Historical Knowledge.
\end{abstract}




\section{Variações sobre as ideias de História}

Os estudiosos do conhecimento histórico, em sua maioria demarcam a fundação da história a partir dos estudos de Heródoto, que surgiram no século V antes de Cristo, na Grécia, tendo como conteúdo a descrição da guerra entre Gregos e Persas ( 490-479 A.C.). Para Heródoto a História era mais que uma simples descrição dos eventos em torno de um fato grandioso realizado pelos homens; ela consiste em investigar, em pesquisar na tentativa de encontrar a verdade. (Borges, 1981).

A partir da Grécia a idéia de história sofre uma série de variações, dentro do espaço-tempo das civilizações com seus autores de estilos e de formações das mais diversas, produzindo uma série de definições sobre a mesma conforme demonstramos a seguir.

Marc Bloch, apud Mendes (1993, p. 8), define que:

O objeto da história é por natureza o homem. Melhor: os homens. Mais do que o singular, favorável à abstração, convém a uma ciência da diversidade o plural, que é o modo gramatical da relatividade (...). $\mathrm{O}$ bom historiador, esse assemelha-se ao monstro da lenda. Onde farejar carne humana é que esta a sua caça (...) Ciência dos homens, dissemos nós. É ainda muito vago. Temos de acrescentar: dos homens do tempo. O historiador não pensa apenas o humano. A atmosfera em que o seu pensamento respira naturalmente é a categoria da duração.

A história que não se basta com o singular, mas busca nas suas investidas o sentido da duração dos homens, nas diversas formas de expressão de sua humanidade, materializada nos monumentos e descrita nos documentos, que espelham a trajetória coletiva da cultura humana. É ciência que estabelece a identificação do ser humano dentro das cronologias, ao investigar e interpretar suas lembranças, resgatando suas recordações como "marcas", que ao serem decifradas colocam o homem diante de si, com seu retrovisor de feitos singulares e coletivos, um ser da consciência.

Philippe Ariès (1986: 22) apresenta a seguinte reflexão:

As culturas são, pois, necessariamente diferentes umas das outras, e cabe ao historiador apreender essas diferenças. Como? Através de um jogo de espelhos e de ricochetes, que o historiador vai aprendendo, na sua vida cotidiana. Vejamos um exemplo: leio, num artigo de Paul Veyne, que a alta sociedade romana preferia a adoção à filiação natural para a sucessão numa herança ou num determinado poder. Este fato interessa-me, primeiro, como um traço característico da civilização romana da época. Mas, em seguida, apercebo-me de que a preferência pela adoção desapareceu, durante a idade média e a época moderna, até que nos nossos dias começa a reaparecer. $\mathrm{O}$ fato em si, que é a adoção - 
e a não-adoção - torna-se o revelador de uma diferença fundamental entre várias culturas.

Assim, a cultura pode alterar-se em um mesmo espaço, a mudança pode acontecer dentro de um determinado tempo em uma mesma sociedade. $\mathrm{O}$ fato histórico que em um determinado período, pode ser considerado determinante do comportamento de um grupo social, pode alterar-se, ou até desaparecer; este movimento dentro da trajetória humana, estabelece a diferença cultural entre grupos sociais que habitam a mesma geografia. E o estudioso da história, deve neste caso, estabelecer uma periodização, pois sem este recorte no tempo dificilmente obterá sucesso em sua investigação.

Segundo Ariès ( 1986: 24):

\begin{abstract}
A história é, e deve continuar a ser, o conhecimento das aparências, cuja ilusão não deve denunciar, mas da qual deve descobrir os elementos que, muitas vezes, estão ocultos e que dela fazem uma estrutura coerente. $\mathrm{O}$ historiador cedo se apercebe de que existem dois tipos de aparências, as que são manifestas e estão à vista de todos, e as ocultas, subterrâneas, apenas notadas pelos seus contemporâneos.
\end{abstract}

Então, o produtor do conhecimento histórico deve ocupar-se das "aparências", buscando dimensionar o que está na "vitrine", visível e contextual e, por outro lado, dar conta da escavação dos elementos acumulados ao longo das etapas e dos períodos componentes do passado, que podem ser desenterrados, pela interpretação das obras mais clássicas e de fontes primárias investigadas e devidamente identificadas.

Todo conhecimento científico traz a marca de seu autor, a história no decorrer do tempo e das culturas, é marcada pela personalidade, pela formação e pelos interesses de seus autores, que situados em estados e instituições, apresentavam ora estudos historiográficos de fidelidade às determinações de grupos dominantes, ora estudos críticos e revolucionários.

Georges Duby (1986:14) faz uma análise crítica da função e do desenvolvimento da história:

Estamos aqui perante a questão da função da história. Para que serve a história? A história é, antes de mais nada, um divertimento: o historiador sempre escreveu por prazer e para dar prazer aos outros. Mas também é verdade que a história sempre desempenhou uma função ideológica, que foi variando ao longo dos tempos. Para Raoul Glaber, essa função consistia numa interpretação moral dos fatos: narrando os acontecimentos do passado, pretendia-se mostrar aos homens como é que Deus queria que eles agissem. Esta função de pedagogia moral manteve-se por muito tempo - Michelet, quando ensinava no Collège de France, ocupava a catédra de História e de Moral. 
A história enquanto construção de um conhecimento sobre o homem, sofre as marcas das idéias no decorrer do tempo, o conjunto de idéias dentro de uma sociedade em geral representam interesses de grupos e determinam o desenvolvimento das políticas, do público e possivelmente de regras de cunho moral; que acabam fazendo parte da interpretação constante na obra dos historiadores em diversas épocas.

Dizemos que, apesar das variações da história nos seus diversos períodos da trajetória humana, um ponto comum é a tentativa dos historiadores de colocar o homem diante de si, garantindo os elementos mais importantes no retrovisor, para que, todos ao lidarem com os estudos historiográficos, encontrem um pouco de sua memória individual e coletiva.

\section{Construção do Conhecimento Histórico}

As idéias e ações humanas são objeto de busca do historiador. O homem é o centro da construção do conhecimento histórico, o homem situado no tempo e no espaço de uma cultura, de uma civilização, de uma sociedade.

O processo de investigar a história, busca nas suas investidas o sentido da duração dos homens, nas diversas formas de expressão de sua humanidade, materializados nos monumentos e descritos nos documentos, que espelham a trajetória coletiva da cultura humana.

Tradicionalmente os estudos históricos partem da investigação dos eventos do passado, coletando e tratando documentos, que são as evidências da ação dos agentes históricos em um determinado tempo e espaço de uma civilização. Em, geral os documentos são representados por cartas, ofícios, decretos, atas, legislações, etc.

Espaço e tempo são duas categorias que se destacam na delimitação dos estudos históricos. A dimensão espacial está relacionada com a necessidade de localização geográfica da sociedade ou civilização escolhida para o desenvolvimento do estudo; segundo Mendes (1993:144):

A delimitação espacial de qualquer estudo histórico impõe-se, sobretudo, devido a dois fatores: impossibilidade de se extrapolarem conclusões de uma área estudada para outra que não tenha sido objeto de estudo; uma segunda impossibilidade - de ordem prática e inerente à própria natureza humana - prende-se com o estudo de áreas demasiado extensas. Com efeito, tratando-se de um quadro geográfico excessivamente amplo, encontrar-se-ão dificuldades, por vezes 
insuperáveis, a nível do conhecimento - o qual, sempre que possível, deve ser direto - da realidade em foco, da pesquisa das fontes e do tratamento de dados.

Uma outra categoria fundamental na construção das historiografias é o tempo. A dimensão temporal torna-se imprescindível uma vez que dificilmente um pesquisador apresenta condições de estudar múltiplas cronologias, então a demarcação cronológica é inevitável para que a pesquisa alcance viabilidade e validade.

Os materiais do passado são as fontes de abastecimento da produção do conhecimento histórico e a única maneira de orientar a investigação histórica no tempo presente. As fontes históricas podem apresentar-se em várias facetas: vestígios arqueológicos, pré-históricos; monumentos artísticos, arquitetônicos, industriais e comemorativos; testemunhos, apresentados como prova e os documentos - todo esse material genericamente denominado de "fontes", são a razão da existência da investigação histórica (MENDES,1993).

As fontes históricas, em geral, apresentam-se como dados, que evidenciam um tempo-espaço, o que convencionamos chamar de uma época da cultura humana. A possibilidade de um homem contemporâneo, estudioso ou não, de se localizar no passado é devido aos vestígios e evidências deixados por outros homens nas diversas formas de documentar a trajetória da civilização humana.

Para Schorske (2000: 13)

Pensar com a história não é o mesmo que pensar sobre a história, como uma forma geral de produzir sentido. Isso é o que os filósofos ou teóricos da história fazem. Pensar com a história implica o emprego dos materiais do passado e das configurações em que os organizamos e compreendemos para nos orientar no presente. Em um modo, pensamos com o produto substantivo da investigação histórica, com as imagens que formamos do passado, a fim de nos definir por diferença ou semelhança a ele.

Assim, a investigação histórica carece de uma delimitação no tempo e no espaço de uma sociedade, de uma civilização, de um grupo humano; sob pena de naufragar no oceano panorâmico dos "estudos universais", que pretensiosamente tentam esgotar questões em torno de personagens, fatos e eventos, com a ilusão de se criar uma "grande história" (Paixão, 2001)

A problematização na ciência histórica caminha na direção de uma seleção dos dados de maneira a compor uma sucessividade de eventos que sejam capazes de traduzirem as ações e as expressões dos agentes históricos do passado, por meio do estudo realizado no tempo presente, onde está localizado o investigador que é o 
responsável pela seleção de acordo com o recorte eleito para a definição de seu objeto de estudo.

Em torno de um problema histórico selecionado, geralmente, giram os agentes históricos, a correlação de forças entre estes, a circulação de idéias, o conhecimento produzido e acumulado nas obras (teoria), e o tipo de sociedade na qual se desenvolve o evento, com suas características culturais.

Buzzi (1994: 72) destaca que:

A história é a preocupação do homem, a investigação de sua possibilidade, o devagar de seu constituir-se ... A árvore fala da natureza; a história, do homem. A árvore de mil folhas, flores e frutos apresenta o florescimento da natureza; a história, o hominizar-se do homem. História gasta tempo para fazer o homem.

Dois grandes caminhos vêm sendo trilhados pelos pesquisadores e estudiosos da história: o método historiográfico analítico e o método historiográfico globalizante. $\mathrm{O}$ primeiro caminho, constitui-se em um percurso por dentro da história com um itinerário parcial (história parcelar), onde a delimitação de um tempo (cronologia), dentro de uma determinada sociedade (espaço), passa a ser imprescindível para início do estudo e da investigação, do conhecimento histórico acumulado, em busca de resposta ao problema proposto, sem pretensão de produzir uma "grande história". O outro caminho busca a construção de uma história de longo alcance temporal e geográfico, com o intuito de compor uma história total.

Entendemos que a demarcação espaço, tempo e personagens, é uma exigência do fazer científico, que nos ensina cotidianamente, que não é possível com um projeto de pesquisa dar conta da história total (global), mas que, o caminho mais seguro, consiste em tentar uma compreensão da parte, buscando a universalização do estudo tomando como referência a teoria acumulada pelos historiadores.

\section{Considerações Finais}

Os caminhos da história são diversos, é certo, porém, entendemos que uma posição pode ser anunciada após alguns anos trabalhando com estudos historiográficos. Dificilmente o estudioso da história e de suas variantes (história da educação; história econômica; história da ciência; história da psicologia; etc.), construirá uma história total (global), capaz de dar conta de uma grande época, de uma sociedade inteira com suas 
múltiplas determinações econômicas, políticas e sociais. Alguma lacuna há de ficar, mesmo que o método possa ser plenamente utilizado.

Faz parte da natureza do processo de construção do conhecimento científico, em qualquer área, a necessidade do pesquisador de delimitar o seu problema, dentro de um contexto mais amplo, elegendo um foco para aprofundar e avançar com seu estudo, com o apoio teórico-conceitual das obras de outros estudiosos, porque como nos diz um mote antigo, mas válido até os dias de hoje: "Sem teoria não se constrói o conhecimento científico", nem é possível universalizar o estudo realizado.

O aprendizado de lidar com as possibilidades de construção do conhecimento histórico por meio do método historiográfico analítico parcelar começou na disciplina Teorias da História, ministrada no Programa de Pós-Graduação em Educação da FFC/UNESP, pelo Dr. Ivan Aparecido Manuel, e foi ganhando aprimoramento com a pesquisa para a construção da Tese, onde investigamos a relação positivismo e educação em uma parcela do tempo-espaço do século XIX, o que culminou com o trabalho intitulado: "O Positivismo e a Educação no Brasil" (UNESP, 1998); com base na experiência de investigação proporcionada pela construção da Tese, desenvolvemos um projeto de pesquisa sobre "A Moral Positivista na Sociedade Brasileira do Século XIX" (UNAMA, 2001), que foi publicado em forma de Livro com o mesmo título pela Editora UNAMA (ISBN 85-86783-72-2); trabalhamos em uma outra pesquisa na mesma linha teórico-metodológica, sobre "Os Sentidos e Significados da Moral Positivista nas Políticas Públicas da Educação Brasileira do Século XIX" (UNAMA, 2002/2003), que foi publicada como capítulo do Livro Pesquisa em Educação no Pará, organizado pelo Dr. Ronaldo Marcos de Lima Araujo, para Editora da Universidade Federal do Pará EDUFPA, no ano de 2003 (ISBN: 85-247-0246-X); em 2004 publiquei o capítulo intitulado "A Reforma da Instrução Pública de Benjamin Constant e os Elementos da Moral Positivista", no Livro Educação e Conhecimento na Amazônia, publicação da Editora da UNAMA (ISBN 85-86783-94-3); o mais recente trabalho circunscrito a essa trilha metodológica de construção do conhecimento histórico válido, faz parte do projeto "A Pesquisa Educacional na Amazônia: um estudo sobre epistemologias e metodologias que servem de suporte à produção do conhecimento em educação nas universidades da Amazônia Paraense", investigação historicamente delimitada, em período composto por uma parcela dos anos 80 do Século XX e uma outra parcela correspondente a primeira década do século XXI - projeto este, desenvolvido no Estágio de Pós-Doutorado no Grupo de Estudos e Pesquisas em Filosofia da Educação (PAIDEIA) da Faculdade de Educação da Universidade Estadual de Campinas - FE/UNICAMP, no período de 2010 2011, sob a Supervisão do Prof. Dr. Silvio Ancízar Sánchez Gamboa.

Assim, desse tempo de aprendizagem sobre a pesquisa histórica, fica como destaque o método histórico analítico parcelar, como um caminho que nos possibilitou a produção e a publicação de uma série de estudos historiográficos válidos, que baseados 
nos princípios da história parcelar, buscam dar conta por meio da investigação de dados de uma determinada época, de produtos da ação e expressão de personagens históricos situados no tempo-espaço de uma sociedade, acreditando que a reflexão crítica de eventos do passado considerando as suas múltiplas determinações e suas fronteiras delimitadas cronologicamente, possam vir a nos proporcionar um maior entendimento dos fenômenos produzidos pelas "culturas" humanas na relação do tempo-espaço do passado com o tempo-espaço do presente.

\section{Referências}

ARAUJO, Ronaldo Marcos de Lima (Org.). Pesquisa em Educação no Pará. Belém: EDUFPA, 2003.

ARIÈS, P. Uma nova educação do olhar. In: DUBY, G. et al. História e nova história. Lisboa: Teorema, 1986, p. 21-31.

BORGES, V. P. O que é história. $3^{\text {a }}$ ed. São Paulo: Brasilense, 1981.

BUZZI, A. R. Introdução ao pensar. Petrópolis: Vozes, 1994.

DUBY, G. et al. História e nova história. Lisboa: Teorema, 1986.

MENDES, J.M.A. A história como ciência. 3ª ed. Coimbra: Coimbra Editora,1993.

PAIXÃO, C. J. O Positivismo e a Educação no Brasil. Tese (Doutorado em Educação). Faculdade de Filosofia e Ciência da Universidade Estadual Paulista - FFC/UNESP, Campus de Marília, Marília - São Paulo, 1998.

------ . O Positivismo ilustrado no Brasil. Revista Trilhas, Belém, v. 1, n. 2, p. 21-27, nov., 2000.

A moral positivista e o pensamento educacional no Brasil do Século XIX. São Luís/MA: Cd-Rom do XV EPENN/ UFMA, 2001.

------------ . A Moral Positivista no Brasil do Século XIX. Belém: Editora UNAMA, 2004.

21-27, nov., 2000.

A moral positivista e o pensamento educacional no Brasil do Século XIX. São Luís/MA: Cd-Rom do XV EPENN/ UFMA, 2001. 
---------- . Os Sentidos e Significados da Moral Positivista nas Políticas Públicas da Educação Brasileira do Século XIX. In: ARAUJO, Ronaldo Marcos de Lima (Org.) Pesquisa em Educação no Pará. Belém: EDUFPA, 2003.

----------- . A Reforma da Instrução Pública de Benjamin Constant e os Elementos da Moral Positivista. In: PAIXÃO, C. J. Educação e Conhecimento na Amazônia. Belém: Editora UNAMA, 2004.

PAIXÃO, C. J. Caminhando no Território da História. Revista Estudos-Humanidades da Universidade Católica de Goiás - UCG, v. 30, n. 3, p. 445-453, mar., 2003.

SCHORSKE, C. E. Pensando com a história. São Paulo: Companhia das Letras, 2000. 